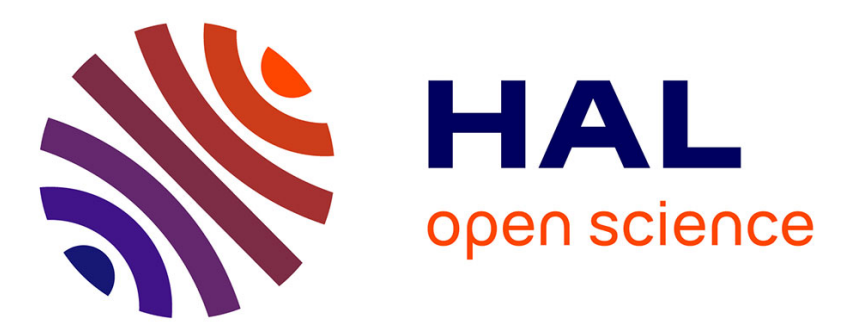

\title{
Behavioral thermoregulation in a non human primate: effects of age and photoperiod on temperature selection.
}

F. Aujard, M. Séguy, J. Terrien, R. Botalla, S. Blanc, M. Perret

\section{To cite this version:}

F. Aujard, M. Séguy, J. Terrien, R. Botalla, S. Blanc, et al.. Behavioral thermoregulation in a non human primate: effects of age and photoperiod on temperature selection.. Experimental Gerontology, 2006, 41 (8), pp.784-92. 10.1016/j.exger.2006.06.001 . hal-00111029

\author{
HAL Id: hal-00111029 \\ https://hal.science/hal-00111029
}

Submitted on 3 Nov 2006

HAL is a multi-disciplinary open access archive for the deposit and dissemination of scientific research documents, whether they are published or not. The documents may come from teaching and research institutions in France or abroad, or from public or private research centers.
L'archive ouverte pluridisciplinaire HAL, est destinée au dépôt et à la diffusion de documents scientifiques de niveau recherche, publiés ou non, émanant des établissements d'enseignement et de recherche français ou étrangers, des laboratoires publics ou privés. 
Behavioral thermoregulation in a non human primate: effects of age and photoperiod on temperature selection

Fabienne Aujard ${ }^{\mathrm{a}, *}$, Maud Séguy ${ }^{\mathrm{a}}$, Jérémy Terrien ${ }^{\mathrm{a}}$, Roger Botalla ${ }^{\mathrm{a}}$, Stéphane Blanc ${ }^{\mathrm{b}}$, Martine Perret ${ }^{\mathrm{a}}$

a'Mécanismes Adaptatifs et Evolution, UMR CNRS/MNHN 5176, 4 avenue du Petit Château, 91800 Brunoy, France

b Institut Pluridisciplinaire Hubert Curien, Département d'Ecologie, Physiologie et Ethologie, UMR CNRS-ULP 7178, 23 rue Becquerel, 67087 Strasbourg, France

Correspondence to : Fabienne Aujard, Mécanismes Adaptatifs et Evolution, UMR CNRS/MNHN 5176, 4 avenue du Petit Château, 91800 Brunoy, France. Tel. 33160479237 - Fax. 33160468118 - e-mail. fabienne.aujard@wanadoo.fr

\section{Running title}

Behavioral thermoregulation and aging

\section{Key words}

Behavioral thermoregulation, thermal gradient, body temperature, temperature selection, daily rhythm, aging, Microcebus murinus, primate 


\section{ABSTRACT}

Deficits in autonomic thermoregulatory capacities have been identified in aged humans and animals, but little is known about the effect of aging on behavioral thermoregulation and the potential effect of season. Preferred ambient temperature $\left(T_{a}\right)$ in a thermal gradient (available $\mathrm{T}_{\mathrm{a}} \mathrm{s}$ from 10 to $30^{\circ} \mathrm{C}$ ) was measured in the mouse lemur, a nocturnal Malagasy primate. Male mouse lemurs (40 adults and 40 aged) were studied under short (SP, resting season) and long photoperiod (LP, breeding season). Additionally, daily body temperature rhythm was telemetrically recorded in 30 individuals of both age categories. In adults exposed to SP, a choice for warm climates was observed, with a mean diurnal $\mathrm{T}_{\mathrm{a}}$ of $26^{\circ} \mathrm{C}$. Day-night differences in selected $\mathrm{T}_{\mathrm{a}}$ occurred only in animals exposed to SP. In LP, selection of a warm environment did not seem to be a necessary factor for maintenance of normothermia. Aged animals selected warmer $\mathrm{T}_{\mathrm{a}} \mathrm{s}$ than adults during the night like during the day, whatever the photoperiod. In relation to changes in body temperature rhythm according to age, aged animals would select warmer environments possibly to compensate autonomic deficiencies. Further studies on age-related changes in hormonal and cellular functions involved in energy balance and thermoregulation will help decipher the causes of insufficient responses to thermal stress observed in the elderly. 


\section{INTRODUCTION}

Thermoregulation involves the use of autonomic and behavioral mechanisms, that allow the individual to adapt to changes in ambient temperature while maintaining its metabolic rate minimal (Gordon, 1984; Gordon et al., 1986). There is compelling evidence suggesting that deficits in thermoregulation occur in aged humans (Pandolf, 1997; Young and Lee, 1997; Kenney and Munce, 2003) and in laboratory animals (Shefer and Talan, 1997; Florez-Duquet and McDonald, 1998). Indeed, exposure to thermal stress induces a higher susceptibility for hypo- or hyperthermia in the elderly, reflecting deficits in both autonomic and behavioral thermoregulation (Anderson et al., 1996). The elderly have a reduced rate of sweat secretion, reduced metabolic responses and less effective peripheral thermoregulatory responses. Moreover, during daytime, the elderly regulate their indoor ambient temperature less precisely (Collins et al., 1981) and their thermal perception is less sensitive especially in summer (Natsume et al., 1992). The ability to make behavioral adjustments when exposed to low or high temperatures decreases with age and this would greatly contribute to the insufficient thermoregulatory responses and discomfort observed in the elderly (Van Someren et al., 2002). An accurate thermal choice is crucial for optimal energy saving during the night and for a sleep of good quality (Van Someren, 2000; Raymann et al., 2005). Although the impact of altered thermoregulatory responses on morbidity and mortality in the elderly is acknowledged, mechanisms accounting for such functional changes with aging are still unknown.

For a better understanding of age-related alterations in behavioral thermoregulation, we studied temperature selection in a thermal gradient in a non human primate, the mouse lemur (Microcebus murinus). The mouse lemur is a small nocturnal Malagasy prosimian primate. To cope with the seasonality in climatic conditions and food availability that occurs in its natural 
habitat, the mouse lemur exhibits seasonal rhythms in most of its physiological and behavioral functions studied so far (Perret, 1992, Aujard et al., 1998, Perret and Aujard, 2001b). The biological rhythms of the mouse lemurs are highly dependent on the photoperiod. Day lengths longer than $12 \mathrm{~h}$ are stimulatory, leading to sustained activity of both behavioral and physiological functions, including metabolic and reproductive functions, whereas day lengths shorter than $12 \mathrm{~h}$ result in complete gonadal regression, fattening and reduced behavioral activities (Perret, 1992). Adaptive traits in thermoregulatory functions have been well documented in this species. The daily rhythm in body temperature is characterized by high levels during the nocturnal period of activity and low levels during the diurnal rest, with a phase of hypothermia occurring during the first half of the daytime (Perret and Aujard, 2001a). Daily hypothermia is a key mechanism for the mouse lemur, that adjusts its energy expenditure through modulation of its body temperature level (Séguy and Perret, 2005b). Thermoregulatory functions vary according to photoperiod and ambient temperature (Aujard et al., 1998; Perret et al., 1998; Aujard and Vasseur, 2001; Séguy and Perret, 2005b), food availability (Séguy and Perret, 2005b) and social factors (Séguy and Perret, 2005a). Thermoregulatory responses involve the use of nonshivering thermogenesis in this primate which possesses brown adipose tissue (Génin et al., 2003). In addition to advanced autonomic thermoregulatory responses, the mouse lemur has developed particular behaviors that modulate its energy expenditures. Mainly solitary during the night, mouse lemurs sleep in buffered tree holes during the day. The choice for an insulating tree hole increases the energy savings of the animal (Schmid, 1998). In addition, mouse lemurs gather in nests and this nest sharing behavior reduces even more the energy expenditure of each individual. The amount of energy saved by nesting varied according to season (Perret, 1998).

With a life span of 8-10 years in captivity, the mouse lemur has been proposed as one of the main models for the study of Alzheimer's disease in non human primates (Bons et al., 2005). 
In this species, cognitive decline associated with cerebral atrophy is observed in both physiological and pathological aging (Dhenain et al., 2003). Some behavioral activity parameters show a decrease with aging (Aujard and Perret, 1998; Némoz-Bertholet and Aujard, 2003). Endocrine functions are also altered with aging. Aged animals show a decrease in sexual hormones (Aujard and Perret, 1998), melatonin (Aujard et al., 2001) and S-DHEA (Perret and Aujard, 2005). Daily and seasonal biological rhythms are altered in aged mouse lemurs. The daily rhythm of locomotor activity is fragmented and of reduced amplitude in aged animals compared to adults (Cayetanot et al., 2005; Aujard et al., 2006). An age-related decrease in amplitude has also been demonstrated in the seasonal rhythms of body mass, basal metabolic rate and testosterone (Perret, 1997; Aujard et al., 2001; Perret and Aujard, 2006). To date, no data is available on thermoregulatory processes in aged mouse lemurs. Owing to the importance of such processes for survival and longevity, further studies are clearly needed.

The present study investigated the effects of aging on behavioral thermoregulation by comparing ambient temperature preference between adult and aged mouse lemurs. Furthermore, experiments were carried out in two different photoperiods to examine the seasonal differences in temperature selection.

\section{METHODS}

\section{Animals}

The male gray mouse lemurs (Microcebus murinus) used in this study were born in the laboratory breeding colony of Brunoy (MNHN, France, license approval № A91.114.1). General conditions of captivity were maintained constant: ambient temperature $\left(24-26^{\circ} \mathrm{C}\right)$, relative humidity (55\%), and food was available ad libitum (including fresh fruits, a milky 
mixture and meal worms). In captivity, seasonal variations of physiological functions can be entrained by alternating 6-month periods of long photoperiod (14 h of light / day, LP) and short photoperiod (10 h of light / day, SP) under artificial light (fluorescent tubes during the day and dim red light during the night). Animals reach sexual maturity at the age of 6 months, before they enter in their $1^{\text {st }}$ period of long days (breeding season). Data from survival curves obtained in the breeding colony have demonstrated that the half life time (50\% survival) occurred at $5.0 \pm 0.3$ years in this species (Perret, 1997). This criteria is usually used to separate the adult population from the aged. After the age of 5 years, mouse lemurs begin to show typical morphological and physiological modifications related to aging (Perret, 1997; Perret and Aujard, 2006). Therefore, mouse lemurs are considered as aged when they are more than 5 years of age. In the present study, adult animals were 1 to 4 years of age and aged animals were 5 to 8 years of age. All animals were tested after at least 1 month of exposure to a given photoperiod, a time lapse necessary for their complete physiological adaptation to the photoperiod (Perret, 1992). All mouse lemurs were exposed to the routine of the breeding colony and were maintained in social groups before and after testing. All experiments were carried out in accordance with the European Communities Council Directive (86/609/EEC).

\section{Temperature selection in a thermal gradient}

Forty animals were tested under SP exposure (adults: mean age \pm SEM: $2.5 \pm 0.3$ years, body weight \pm SEM: $103 \pm 3$ g, $N=20$; aged: mean age \pm SEM: $5.9 \pm 0.2$ years, body weight \pm SEM: $100 \pm 4 \mathrm{~g}, N=20$ ) and 40 under LP exposure (adults: mean age \pm SEM: $2.7 \pm 0.3$ years, body weight \pm SEM: $79 \pm 3 \mathrm{~g}, N=20$; aged: mean age \pm SEM: $5.8 \pm 0.2$ years, body weight \pm SEM: $85 \pm 4 \mathrm{~g}, N=20)$. Body mass of animals were higher in SP than in LP $(\mathrm{t}(78)=$ $-5.51, p<0.001)$. Body mass did not differ significantly between adult and aged animals in 
each photoperiod $(\mathrm{LP}: \mathrm{t}(38)=-1.22$, NS; SP: $\mathrm{t}(38)=0.79$, NS). Thus, the age related differences observed in this study could not be attributed to differences in body weight.

Temperature selection was estimated using a thermal gradient adapted to the mouse lemur and created by R. Botalla (Fig. 1). The apparatus was placed in a $T_{a}$ controlled room. It consisted of a plastic structure (100 cm long) divided in 5 chambers $(12 \mathrm{~cm} \mathrm{x} 12 \mathrm{~cm})$. The animal could enter each chamber via a curved tube. The device was placed in a cage $(120 \mathrm{~cm}$ x $50 \mathrm{~cm}$ x $35 \mathrm{~cm}$ ) provided with branches. Food was available ad libitum. The light-dark cycle was set according to the cycle of the tested animals and was provided by cool fluorescent tubes. The $T_{a} s$ in the gradient were generated by a cooling/warming water system circulating in the back of the chambers. Temperatures of $10^{\circ} \mathrm{C}, 15^{\circ} \mathrm{C}, 20^{\circ} \mathrm{C}, 25^{\circ} \mathrm{C}, 30^{\circ} \mathrm{C}$ were set in each chamber with a precision of $\pm 0.2^{\circ} \mathrm{C}$, using a calibrated thermocouple ( $\mathrm{K}$ type). Position of the animal was detected every $5 \mathrm{sec}$ by passive infrared sensors (Honeywell \#SEP8705-003 and \#SDP8405-014) and data were stored in a computerized system (developed in the laboratory by R. Botalla). Based on nest occupancy, temperature selection was averaged on 15-min intervals for further analysis.

None of the mouse lemurs used in this study had any prior experience with the thermal gradient device. Animals were weighed prior to the experiment. They were then placed in the gradient $2 \mathrm{~h}$ before lights off for habituation. Recording started with the beginning of the night and stopped the next day $6 \mathrm{~h}$ after the beginning of the light phase, a time necessary for the animal to complete its phase of hypothermia. To prevent odorant overload, the apparatus was cleaned between each experiment.

\section{Recording of body temperature}

In this experiment, 8 adult (mean age \pm SEM: $1.8 \pm 0.1$ years) and 7 aged mouse lemurs (mean age \pm SEM: $5.5 \pm 0.2$ years) exposed to SP and 8 adult (mean age \pm SEM: $1.3 \pm 0.1$ 
years) and 7 aged mouse lemurs (mean age \pm SEM: $5.6 \pm 0.2$ years) exposed to LP were used. Body mass of animals varied between SP and LP $(\mathrm{t}(28)=-2.14, p<0.05)$. Body mass did not differ significantly between adult and aged animals in each photoperiod (LP: t(13) = -1.79, NS; SP: $t(13)=1.22$, NS).

Body temperature was recorded by telemetry using radio sensor-transmitters (TA10TA-F20 Data Sciences International, Transoma Medical, St Paul, Minn, USA) implanted in the visceral cavity under anesthesia (Valium 2 mg / 100 g i.m., Imalgen 50010 mg / 100 g i.p). After awakening, mouse lemurs were housed individually in a cage containing a receiver board. Cages were placed in a room with filtered air and illuminated with cool fluorescent lamps during the light phase and with a dim red light during the dark phase. The recording period began 14 days after surgery and lasted 10 days. Two receiver boards positioned on opposite sides of the cage collected radio frequencies signals. Body temperature was recorded for $10 \mathrm{~s}$ every 5 min. Data were collected using a computerized data acquisition system (Dataquest LabPro v.3.11, Data Sciences International, Transoma Medical, St Paul, Minn, USA).

\section{Statistical analysis}

Results are given in mean \pm SEM. Analyses were conducted using SYSTAT for Windows. Comparisons in which $p<0.05$ were considered to differ significantly. Student's unpaired or paired t-tests were used to assert significant variations in all studied parameters. Relationships between different parameters were tested using Pearson correlation test. To compare difference in distribution of chosen nests between observed and theoretical distribution, we used the Kolmogorov-Smirnov one-sample test.

\section{RESULTS}




\section{General activity pattern}

Once they were placed in the apparatus and after lights off, all mouse lemurs exhibited a high level of exploratory behaviors revealed by repeated visits in the 5 available nests. Time spent in the nests during the night time varied according to season and age (Fig. 2). In both photoperiods, aged animals spent significantly more time in a nest than adult animals (LP: $\mathrm{t}(38)=-4.5, p<0.001$; SP: $\mathrm{t}(38)=-4.48, \mathrm{p}<0.001)$. Whatever the age category, mouse lemurs spent more time in a nest when exposed to SP than to LP (adults: $\mathrm{t}(38)=-3.06, p<$ 0.01 ; aged: $\mathrm{t}(38)=-2.58, p<0.05)$. At least $30 \%$ of the night time was spent inside a nest and, on average, $4.4 \pm 0.2$ nests were visited by the animals. Therefore, we can consider that all animals have experienced the temperature conditions of the different nests before they entered a nest for the diurnal phase. At the end of the night phase, all animals entered a nest for their diurnal sleep that they did not leave until they were removed from the apparatus $6 \mathrm{~h}$ later.

\section{Thermal choice under long photoperiod}

Fig. 3A represents the profile of temperature selection over the time course of the experiment in mouse lemurs exposed to LP. In adult animals, the average preferred $\mathrm{T}_{\mathrm{a}}$ was $23.3 \pm 0.9^{\circ} \mathrm{C}$ during the night and $21.1 \pm 1.8^{\circ} \mathrm{C}$ during the day. No significant difference was found between the preferred $\mathrm{T}_{\mathrm{a}} \mathrm{s}$ during the night and during the day $(\mathrm{t}(19)=1.25$, NS). The distribution of preferred $\mathrm{T}_{\mathrm{a}} \mathrm{s}$ during the day was not significantly different from a random distribution ( $\mathrm{D}=0.20, \mathrm{~N}=20, \mathrm{NS}$ ), owing to the large interindividual variability in the $T_{a}$ selection. Indeed, only $55 \%$ of the adult animals chose the warmest nests ( 25 and $30^{\circ} \mathrm{C}$ ) to spend their diurnal sleeping time and some individuals were found sleeping in the coldest nests. Finally, individual values of selected $T_{a}$ were not correlated with body weight $(r(18)=$ 0.338, NS - Fig. 5A). 
In aged animals, there was no significant variation between night and day preferred $\mathrm{T}_{\mathrm{a}} \mathrm{s}(\mathrm{t}(19)$ $=-0.54$, NS - Fig. 3A). The average preferred $\mathrm{T}_{\mathrm{a}}$ was $26.1 \pm 0.8^{\circ} \mathrm{C}$ during the night and 26.7 $\pm 0.9{ }^{\circ} \mathrm{C}$ during the day. $\mathrm{T}_{\mathrm{a}}$ selected by aged animals were significantly higher than those selected by adult animals during both night $(\mathrm{t}(38)=-2.39, p<0.05)$ and day $(\mathrm{t}(38)=-2.89, \mathrm{p}$ $<0.01$ - Fig. 4). The distribution of preferred $\mathrm{T}_{\mathrm{a}} \mathrm{s}(\mathrm{D}=0.40, \mathrm{~N}=20, p<0.01)$ was significantly skewed towards $30^{\circ} \mathrm{C}$, with $80 \%$ of the aged animals found in the warmest nests during the day. Like in adult animals, no correlation could be found between preferred $\mathrm{T}_{\mathrm{a}} \mathrm{s}$ and body weight in aged animals $(r(18)=0.136$, NS - Fig. $5 A)$.

\section{Thermal choice under short photoperiod}

In adult animals exposed to SP, a day/night variation in selected $\mathrm{T}_{\mathrm{a}}$ was observed $(\mathrm{t}(19)=$ 3.06, $p<0.01-$ Fig. 3B). Adult animals selected colder $\mathrm{T}_{\mathrm{a}} \mathrm{s}$ during the night $\left(21.7 \pm 1.5^{\circ} \mathrm{C}\right)$ than during the day $\left(26.0 \pm 1.6^{\circ} \mathrm{C}\right)$. The Ta selection during the diurnal sleep was not randomly distributed since $75 \%$ of the tested animals were found in the warmest nests $(\mathrm{D}=$ $0.50, \mathrm{~N}=20, p<0.01)$. Individual values of selected $\mathrm{T}_{\mathrm{a}}$ were negatively correlated with body weight $(r(18)=-0.634, p<0.01)$, meaning that bigger animals selected colder $\mathrm{T}_{\mathrm{a}} \mathrm{s}$ (Fig. 5B). In the aged group, a significant difference between night and day selected $\mathrm{T}_{\mathrm{a}} \mathrm{S}$ was also found $(\mathrm{t}(19)=-2.57, p<0.02)$, with colder selected $\mathrm{T}_{\mathrm{a}} \mathrm{s}$ during the night than during the day (Fig.

3B). Aged animals selected an average $\mathrm{T}_{\mathrm{a}}$ of $27.7 \pm 0.6^{\circ} \mathrm{C}$ during the night and an average $\mathrm{T}_{\mathrm{a}}$ of $29.0 \pm 0.6^{\circ} \mathrm{C}$ during the day. Selected $\mathrm{T}_{\mathrm{a}} \mathrm{s}$ at night were higher in the aged group than in the adult group $(\mathrm{t}(38)=-3.79, p<0.001-$ Fig. 4$)$. The average value of selected $\mathrm{T}_{\mathrm{a}}$ during the day did not differ significantly from the value observed in adults $(\mathrm{t}(38)=-1.79$, NS). In aged animals, selected $T_{a} s$ during the day were significantly skewed towards the warmer values (D $=0.80, \mathrm{~N}=20, p<0.01$ ), with $95 \%$ of the aged animals were found in the warmest 
environments. Like in adult animals, selected $\mathrm{T}_{\mathrm{a}} \mathrm{s}(\mathrm{r}(18)=-0.587, p<0.01)$ were negatively correlated with body weight (Fig. 5B).

Selected $T_{a} s$ at night of animals exposed to SP did not differ from $T_{a} s$ selected by animals exposed to LP, whether they were adult $(t(38)=0.94$, NS) or aged $(t(38)=-1.69$, NS). By contrast, selected $\mathrm{T}_{\mathrm{a}} \mathrm{s}$ during the day were significantly higher in animals exposed to SP than in animals exposed to LP whatever their age category (adult: $\mathrm{t}(38)=-2.12, p<0.05$; aged: $\mathrm{t}(38)=-2.09, p<0.05)$.

\section{Day/night variations in body temperature}

At a constant ambient temperature of $25^{\circ} \mathrm{C}$, a clear daily rhythm of $\mathrm{T}_{\mathrm{b}}$ was recorded under both photoperiods and whatever the age category (Fig. 6). The daily rhythm of $T_{b}$ was characterized by high values during the nocturnal active phase and lower values during the diurnal resting period. In LP, $\mathrm{T}_{\mathrm{b}}$ was significantly lower in aged animals compared to adult animals for both night $(\mathrm{t}(13)=2.46, p<0.05)$ and day $(\mathrm{t}(13)=2.55, p<0.05)$. In SP, no significant difference between the 2 age categories could be found for night $(\mathrm{t}(13)=-0.41$, NS) and day $T_{b}$ values $(t(13)=0.30$, NS). In fact, a differential effect of photoperiod was observed in adult animals, with higher $\mathrm{T}_{\mathrm{b}}$ values in animals exposed to LP than in animals exposed to SP for night $(\mathrm{t}(14)=4.61, p<0.001)$ and day values $(\mathrm{t}(14)=3.09, p<0.01)$. No difference could be found in aged animals for both night $\left(t(12)=1.45\right.$, NS) and day $T_{b}$ levels $(\mathrm{t}(12)=0.71$, NS) according to season. Finally, there was no significant correlation between body weight and night $\mathrm{T}_{\mathrm{b}}\left(\mathrm{r}(13)=0.384\right.$, NS) or day $\mathrm{T}_{\mathrm{b}}(\mathrm{r}(13)=0.411$, NS) in animals exposed to LP. A negative correlation was found between body weight and both night $(\mathrm{r}(13)=$ $-0.532, p<0.05)$ and day $\mathrm{T}_{\mathrm{b}}(\mathrm{r}(13)=-0.516, p<0.05)$ in animals exposed to SP. Under SP exposure, bigger animals had lower $\mathrm{T}_{\mathrm{b}}$ values. 


\section{DISCUSSION}

The temperature gradient apparatus was successfully adapted to the mouse lemur. Its natural tendency for exploration and its spontaneous nesting behavior allowed the gathering of $T_{a}$ selection data throughout the light-dark cycle and in both age categories. $T_{a}$ selection varied according to photoperiod and age in this primate species. A choice for warm climates was observed in adult mouse lemurs exposed to SP, whereas behavioral thermoregulation in LP did not seem useful for maintenance of normothermia. With aging, warmer environments were chosen whatever the photoperiodic state, reflecting the necessity for aged animals to operate both behavioral and autonomic effectors of thermoregulation.

In SP, adult mouse lemurs were found at an average $\mathrm{T}_{\mathrm{a}}$ of $\sim 26^{\circ} \mathrm{C}$ during their diurnal sleep. This temperature is near the lower limit of the thermoneutral zone in this species, where energy expenditure and evaporation are minimal (Aujard et al., 1998). This supports the notion that $\mathrm{T}_{\mathrm{a}}$ selection for the diurnal sleeping period in mouse lemurs is closely related to the animal's metabolic requirement, like it has been shown in mice (Gordon, 1985) and hamsters (Gordon, 1986). During the night, animals were found at an average $\mathrm{T}_{\mathrm{a}}$ of $\sim 22{ }^{\circ} \mathrm{C}$, which is colder than the Ta observed during the day. This is in agreement with data obtained in rodents (Gordon, 1993; Refinetti, 1996, 1998) and marsupials (Song et al., 1998), and could support the idea that animals select a cooler environment to avoid hyperthermia during their active phase. However, mouse lemurs did not perform a significant selection of a particular $\mathrm{T}_{\mathrm{a}}$ during the night, suggesting that energetic requirements during the active nocturnal phase represent less constraints than during the day.

Aged animals exposed to SP selected a higher $\mathrm{T}_{\mathrm{a}}$ compared to adults, with an average selected $\mathrm{T}_{\mathrm{a}}$ of $\sim 29^{\circ} \mathrm{C}$ during their diurnal sleep and an average $\mathrm{T}_{\mathrm{a}}$ of $\sim 28^{\circ} \mathrm{C}$ during their nocturnal active phase. Selection of a warm environment via behavioral thermoregulation aims at 
limiting heat loss and preventing a decline in body temperature in humans (Florez-Duquet and McDonald, 1998) and in rodents (Briese, 1985; Florez-Duquet et al., 2001). The observed result can’t be explained by age differences in body temperature levels, since no significant difference was found in day and night $\mathrm{T}_{\mathrm{b}}$ between adult and aged animals exposed to SP. This result may rather be explained by a higher cost for aged animals to maintain their $\mathrm{T}_{\mathrm{b}}$ in $\mathrm{a}$ normothermic range that should be reflected by a higher energetic cost at a reference $T_{a}$ of $25^{\circ} \mathrm{C}$ or by a shift in the thermoneutral zone towards warmer temperatures. This remains to be demonstrated. Mouse lemurs use brown adipose tissue and nonshivering thermogenesis to warm up from daily hypothermia, by increasing uncoupling protein expression (Génin et al., 2003). A deficit in nonshivering thermogenesis could occur with age in the mouse lemur. A decrease in cold induced brown adipose tissue nonshivering thermogenesis was demonstrated in aged rats (Florez-Duquet et al., 1998; McDonald and Horwitz, 1999) but the concentration of uncoupling protein in brown adipose tissue remained unchanged with aging (Scarpace et al., 1994). An age-related deficit in autonomic thermoregulation could also be the case during the nocturnal active phase, since aged animals significantly selected a warm environment to rest during the night, by contrast to adults. Moreover, an inverse relationship was found between the level of locomotor activity and selected $T_{a}$ in adult rodents (Gordon, 1993). The decrease in the level of locomotor activity demonstrated in aged mouse lemurs (Cayetanot et al., 2005, Aujard et al., 2006) could account for the warmer $T_{a}$ selected during the night by aged mouse lemurs compared to adults.

Differences in $\mathrm{T}_{\mathrm{a}}$ values and distribution were observed according to photoperiod. In LP, adult animals slept at an average $T_{a}$ of $21^{\circ} \mathrm{C}$, which is significantly lower than the selected $T_{a}$ in SP. However, this average value is reflective of the wider range of $T_{a} s$ at which animals were found to sleep. Indeed, no significant choice was found in the distribution of the selected nests in animals exposed to LP, by contrast to SP. It is accepted from studies on laboratory 
rodents that most species select a $T_{a}$ associated with minimal energy expenditure (Gordon, 1985; Gordon et al., 1986). But usually animals are studied under exposure to a 12/12 lightdark cycle and photoperiod was not taken into account in those studies. Our results suggest that, mouse lemurs exposed to LP efficiently maintain their $\mathrm{Tb}$ in a normothermic range via autonomic thermoregulation rather than via behavioral thermoregulation. Physiological state acquired under LP would provide the energetic requirement for body temperature regulation. Therefore, animals would unselectively enter the nests they have access to. In addition, individual values of selected $\mathrm{T}_{\mathrm{a}}$ are correlated to body weight in SP but not in LP, reinforcing the idea of a stronger relation between behavioral and autonomic thermoregulation in SP than in LP.

Under LP, mouse lemurs maintain their body temperature to a higher level than under SP. LP corresponds to the season of sexual activation in male mouse lemurs, with high levels of testosterone (Perret, 1992) and DHEA-S (Perret and Aujard, 2005). Sex steroids have been shown to influence heat production by regulating various metabolic pathways (Gudmundsson et al., 1999; Hampl et al., 2005). In LP, steroids levels are high in the mouse lemur, and this would comfort the hypothesis that autonomic thermoregulation is very effective under this photoperiodic regimen. By contrast, in SP, testosterone and DHEA-S are low (Perret and Aujard, 2005), and behavioral thermoregulation may be necessary for maintenance of normothermia. The less energetic advantage of nest sharing in LP than in SP also comfort this assumption (Perret, 1998). Another potential hormonal actor in the thermoregulatory process is melatonin, known to influence body temperature modulation and sleep induction in humans (Cagnacci et al., 1997; Cajochen et al., 2003) and to be produced during arousal from torpor in hamsters (Larkin et al., 2003). Marked seasonal variations in melatonin level have been demonstrated in the mouse lemur (Perret and Aujard, 2006), which could influence photoperiod-induced thermoregulatory processes. 
With aging, mouse lemurs exposed to LP select warmer $T_{a} s$ than adults throughout the day/night cycle. This is reflected by a significant choice for the warmest nests, corresponding to an average $\mathrm{T}_{\mathrm{a}}$ of $27^{\circ} \mathrm{C}$. This reinforces the idea that behavioral thermoregulation is an additional effector for the maintenance of normothermia in aged mouse lemurs, whatever the photoperiod exposure. Choice for warmer $\mathrm{T}_{\mathrm{a}} \mathrm{s}$ in aged animals is associated with lower day and night body temperature compared to adults. Thermoregulatory deficits in aged mouse lemurs need to be correlated with hormonal changes, since an age-related decrease in testosterone levels and DHEA-S was demonstrated in animals exposed to LP (Aujard et al., 1998; Perret and Aujard, 2005). Moreover, the clear photoperiod difference in behavioral thermoregulation observed in adult animals is blunted in aged animals. Decrease in melatonin secretion with aging has been documented in aged humans (Skene and Swaab, 2003; Mahlberg et al., 2006) and has also been found in aged mouse lemurs (Aujard et al., 2001; Perret and Aujard, 2006). This could account for the reduced amplitude in seasonal variations of various physiological functions observed with aging in the mouse lemur. In conclusion, this study demonstrated that selection for an ambient temperature depended on the photoperiod the mouse lemurs were exposed to. In adults, behavioral thermoregulation was activated during SP, when animals were in their season of sexual rest and fattening. In LP, corresponding to the season of sexual arousal and body weight loss, selection of a warm environment did not seem to be a necessary factor for maintenance of normothermia. With aging, behavioral and autonomic thermoregulatory effectors operated jointly whatever the photoperiod. Aged animals always selected warmer environments than adults. Given normal body temperatures in aged animals, their selection of warmer environments suggests that they rely more on behavioral thermoregulation, which may or may not reflect compensation for possible deficits in autonomic thermoregulation. It would be interesting to perform the same experiment in a thermal gradient shifted towards warmer temperatures to define precisely the 
temperature of comfort for aged animals. Such information would be useful to adapt the condition of captivity of aged animals. Furthermore, in association with these results, studies are needed to determine the mechanisms accounting for such changes with aging. A precise knowledge of age-related changes in hormonal and cellular functions involved in energy balance and thermoregulation, such as IGF-1, leptin, grehlin, body composition, will help decipher the causes of inappropriate responses to thermal stress observed in the elderly. 


\section{Acknowledgements}

This work was supported by Institut de la Longévité et du Vieillissement, Fondation pour la Recherche Médicale and ACI INSERM Neurosciences. 


\section{References}

Anderson, G.S., Meneilly, G.S., Mekjavic, I.B. 1996. Passive temperature lability in the elderly. Eur. J. Appl. Physiol. 73, 278-86.

Aujard, F., Vasseur, F. 2001. Effect of ambient temperature on the body temperature rhythm of male lesser mouse lemurs (Microcebus murinus). Int. J.Primatol. 22(1), 43-56.

Aujard, F., Perret, M., Vannier, G. 1998. Thermoregulatory responses to variations of photoperiod and ambient temperature in the lesser mouse lemur: a primitive or an advanced adaptive character? J. Comp. Physiol. B 168, 540-548.

Aujard, F., Perret, M. 1998. Age-related effects on reproductive function and sexual competition in the male prosimian primate, Microcebus murinus. Physiology and Behavior 64(4):513-519.

Aujard, F., Dhkissi-Benyahya, O., Fournier, I., Claustrat, B., Schilling, A;, Cooper, H. M., Perret, M. 2001. Artificially accelerated aging by shortened photoperiod alters early gene expression (Fos) in the suprachiasmatic nucleus and sulfatoxymelatonin excretion in a primate. Neurosci. 105, 403-412.

Aujard, F., Cayetanot, F., Bentivoglio, M., Perret, M. 2006. Age-related effects on the biological clock and its behavioral output in a primate. Chronobiol. Internat. (in press).

Bons, N., Rieger, F., Prudhomme, D., Fisher, A., Krause, K. H. Microcebus murinus: a useful primate model for human cerebral aging and Alzheimer's disease? Genes Brain Behav. 2006. 5, 120-30.

Briese, E. 1985. Rats prefer ambient temperatures out-of-phase with their body temperature circadian rhythm. Brain Res. 345, 389-393.

Cagnacci, A., Krauchi, K., Wirz-Justice, A., Volpe, A. 1997. Homeostatic versus circadian effects of melatonin on core body temperature in humans. J. Biol. Rhythms 12, 509-517. 
Cajochen, C., Krauchi, K., Wirz-Justice, A. 2003. Role of melatonin in the regulation of human circadian rhythms and sleep. J. Neuroendocrinol. 15, 432-437.

Cayetanot, F., Van Someren, E. W. J., Perret, M., Aujard, F. 2005. Long-term perturbation in the entrainment of the biological clock induces its early aging in a primate. J. Biol. Rhythms 20, 461-469.

Collins, K. J., Exton-Smith, A. N., Dore, C. 1981. Urban hypothermia: preferred temperature and thermal perception in old age. Brit. Med. J. 282, 175-177.

Dhenain, M., Chenu, E., Hisley, C. K., Aujard, F., Volk, A. 2003. Regional atrophy in the brain of lissencephalic mouse lemur primates: measurement by automatic histogram-based segmentation of MR images. Magn. Res. Med. 50, 984-992.

Florez-Duquet, M., McDonald, R. B. 1998. Cold-induced thermoregulation and biological aging. Physiol. Rev. 78, 339-358.

Florez-Duquet, M., Horwitz, B. A., McDonald, R. B. 1998. Cellular proliferation and UCP content in brown adipose tissue of cold-exposed aging Fischer 344 rats. Am. J. Physiol. 274, R196-R203.

Florez-Duquet, M., Peloso, E., Satinoff, E. 2001. Fever and behavioral thermoregulation in young and old rats. Am. J. Physiol. 280, R1457-1461.

Génin, F., Nibbelink, M., Galand, M., Perret, M., Ambid, L. 2003. Brown fat and nonshivering thermogenesis in the gray mouse lemur (Microcebus murinus). Am. J. Physiol. 284, R811-R818.

Gordon, C. J. 1985. Relationship between autonomic and behavioral thermoregulation in the mouse. Physiol. Behav. 34, 687-690.

Gordon, C. J. 1993. Twenty-four hour rhythms of selected ambient temperature in rat and hamster. Physiol. Behav. 53, 257-263. 
Gordon, C. J., Fehlner, K. S., Long, M. D. 1986. Relationship between autonomic and behavioral thermoregulation in the golden hamster. Am. J. Physiol. 251, R320-R324.

Gudmundsson, A., Goodman, B., Lent, S., Barczi, S., Grace, A., Boyle, L., Ershler, W. B., Carnes, M. 1999. Effects of estrogen replacement therapy on the circadian rhythms of serum cortisol and body temperature in postmenopausal women. Exp. Gerontol. 34, 809818.

Hampl, R., Starka, L., Jansky, L. 2005. Steroids and thermogenesis. Physiol. Res. May 24; [Epub ahead of print]

Kenney, W. L., Munce, T. A. 2003. Invited review: aging and human temperature regulation. J. Appl. Physiol. 95, 2598-2603.

Larkin, J. E., Yellon, S. M., Zucker, I. 2003. Melatonin production accompanies arousal from daily torpor in Siberian hamsters. Physiol Biochem Zool. 76, 577-585.

McDonald, R. B., Horwitz, B. A. 1999. Brown adipose tissue thermogenesis during aging and senescence. J. Bioenerg. Biomembr. 31, 507-516.

Natsume, K., Ogawa, T., Sugenoya, J., Ohnishi, N., Imai, K. 1992. Preferred ambient temperature for old and young men in summer and winter. Int. J. Biometeorol. 36, 1-4.

Némoz-Bertholet; F., Aujard, F. 2003. Physical activity and balance performance as a function of age in a prosimian primate (Microcebus murinus). Exp. Gerontol. 38, 407-414.

Pandolf, K. B. 1997. Aging and Human heat tolerance. Exp. Aging Res. 23, 69-105.

Perret, M. 1992. Environmental and social determinants of sexual function in the male lesser mouse lemur (Microcebus murinus). Folia Primatol. 59, 1-25.

Perret, M. 1997 Change in photoperiodic cycle affects lifespan in a prosimian primate (Microcebus murinus). J. Biol. Rhythms 12, 136-145.

Perret, M. 1998. Energetic advantage of nest-sharing in a solitary primate, the lesser mouse lemur (Microcebus murinus). J. Mammal. 79, 1093-1102. 
Perret, M., Aujard, F. 2001a. Daily hypothermia and torpor in a tropical primate: synchronization by 24-h light-dark cycle. Am. J. Physiol. 281, R1925-1933.

Perret, M., Aujard, F. 2001b. Regulation by photoperiod of seasonal changes in body weight and reproductive function in the lesser mouse lemur (Microcebus murinus): differential responses by sex. Int. J. Primatol. 22, 5-24.

Perret, M., Aujard, F. 2005. Aging and season affect plasma dehydroepiandrosterone sulfate (DHEA-S) levels in a primate. Exp. Gerontol. 40, 582-587.

Perret, M., Aujard, F. 2006. Aging and biological rhythms in primates. Med. Sci. 22, 279-283.

Raymann, R. J., Swaab, D. F., van Someren, E. J. 2005. Cutaneous warming promotes sleep onset. Am. J. Physiol. 288, R1589-1597.

Refinetti, R. 1996. Rhythms of body temperature and temperature selection are out of phase in a diurnal rodent, Octodon degus. Physiol. Behav. 60, 959-961.

Refinetti, R. 1998. Body temperature and behavior of tree shrews and flying squirrels in a thermal gradient. Physiol. Behav. 63, 517-520.

Scarpace, P. J., Yenice, S., Tumer, N. 1994. Influence of exercise training and age on uncoupling protein mRNA expression in brown adipose tissue. Pharmacol. Biochem. Behav. 49, 1057-1059.

Schmid, J. 1998. Tree holes used for resting by gray mouse lemurs (Microcebus murinus) in Madagascar: insulation capacities and energetic consequences. Int. J. Primatol. 19, 797809.

Séguy, M., Perret, M. 2005a. Changes in olfactory inputs modify the energy balance response to short days in male gray mouse lemurs. Physiol. Behav. 84, 23-31.

Séguy, M., Perret, M. 2005b. Factors affecting the daily rhythm of body temperature of captive mouse lemurs (Microcebus murinus). J. Comp. Physiol. 175, 107-115. 
Shefer, V. I., Talan, M. I. 1997. Change in heat loss as a part of adaptation to repeated cold exposures in adult and aged male C57BL/6J mice. Exp. Gerontol. 32, 325-332.

Skene, D. J., Swaab, D. F. 2003. Melatonin rhythmicity: effect of age and Alzheimer's disease. Exp. Gerontol. 38, 199-206.

Song, X., Körtner, G., Geiser, F. 1998. Temperature selection and use of torpor by the marsupial Sminthopsis macroura. Physiol. Behav. 64, 675-682.

Van Someren, E. J. W. 2000. More than a marker: interaction between the circadian regulation of temperature and sleep, age-related changes, and treatment possibilities. Chronobiol. Internat. 17, 313-354.

Van Someren, E. J. W., Raymann, R. J. E. M., Schreder, E. J. A., Daanen, H. A. M., Swaab, D. F. 2002. Circadian and age-related modulation of thermoreception and temperature regulation: mechanisms and function implications. Ageing Res. Rev. 1, 721-778.

Young, A. J., Lee, D.T. 1997. Aging and human cold tolerance. Exp. Aging Res. 23, 45-67. 


\section{Figure legends}

Fig. 1. Schematic representation of the thermal gradient set-up placed in the experimental cage. The temperature gradient was created by hot and cold water pumped into each sides of the set-up and conducted by a copper bar. The animal, placed in the cage provided with branches and food, had access to each chamber via a tunnel. Automatic data acquisition recorded the presence of the animal in a chamber and the ambient temperature in each chamber.

Fig. 2. Percentage of the night time spent inside a nest in mouse lemurs placed in the thermal gradient according to photoperiod and age. ${ }^{* * *}: \mathrm{p}<0.001$

Fig. 3. Time-course of selected ambient temperature of adult and aged mouse lemurs in the thermal gradient, when exposed to long photoperiod (A) or short photoperiod (B). $N=20$ in each age category and in each photoperiod.

Fig. 4. Average values of nocturnal and diurnal selected ambient temperatures of adult $(\mathrm{N}=$ 20) and aged $(\mathrm{N}=20)$ mouse lemurs in the thermal gradient, when exposed to either long photoperiod (LP) or short photoperiod (SP). NS: not significant; *: p < 0.05; **: p $<0.01$.

Fig. 5. Relations between individual body weight and selected ambient temperatures in adult ( $N=20)$ and aged $(\mathrm{N}=20)$ mouse lemurs in the thermal gradient, when exposed to either long photoperiod (LP) or short photoperiod (SP). ${ }^{* *}$ : $\mathrm{p}<0.01$. 
Fig. 6. Average values of nocturnal and diurnal body temperatures of adult and aged mouse lemurs exposed to either long photoperiod (LP) or short photoperiod (SP). In each photoperiod, 8 adult and 7 aged mouse lemurs were tested. NS: not significant; *: p < 0.05. 
Fig. 1

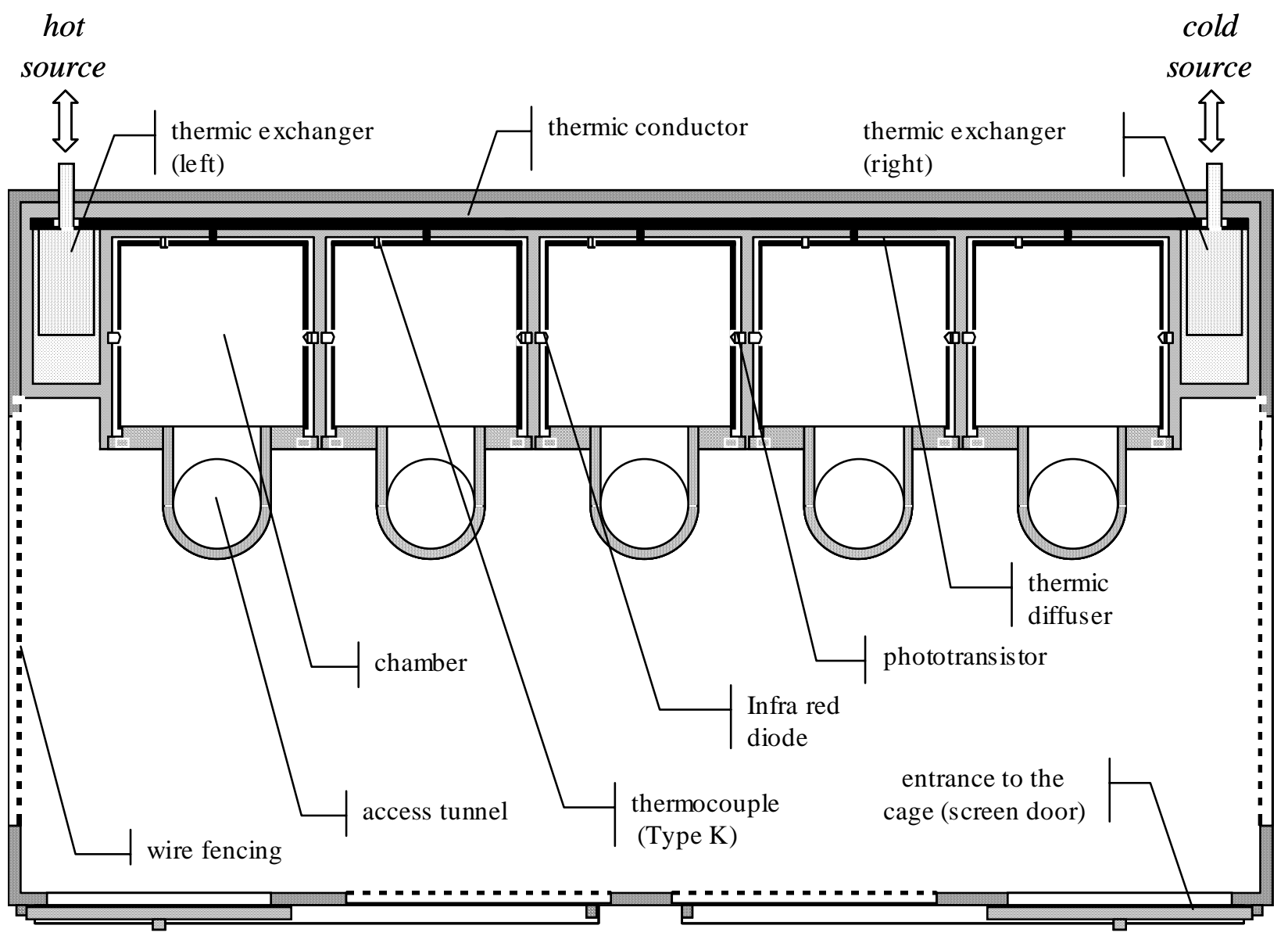


Fig. 2

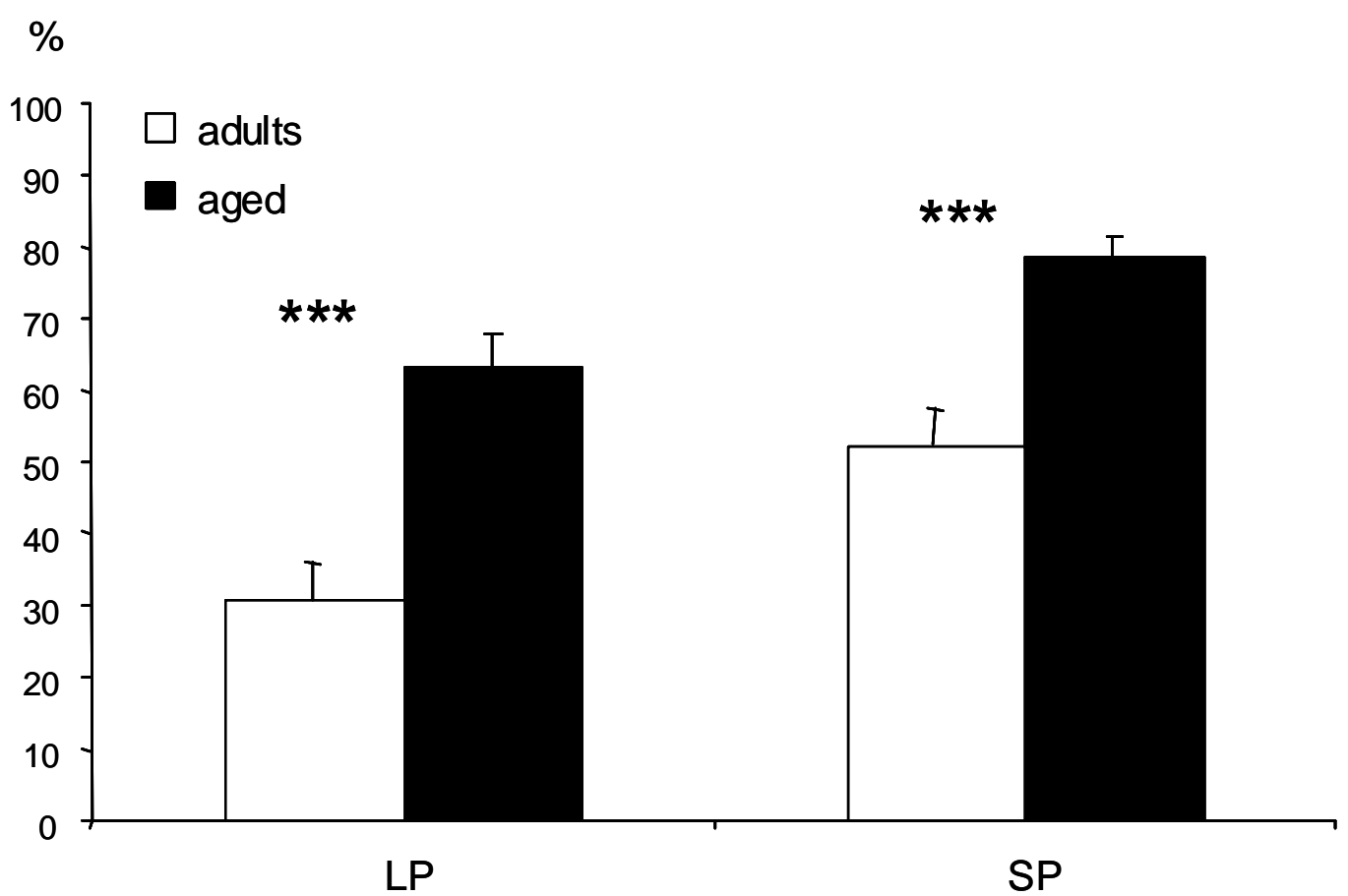


Fig. 3

A

adults

aged
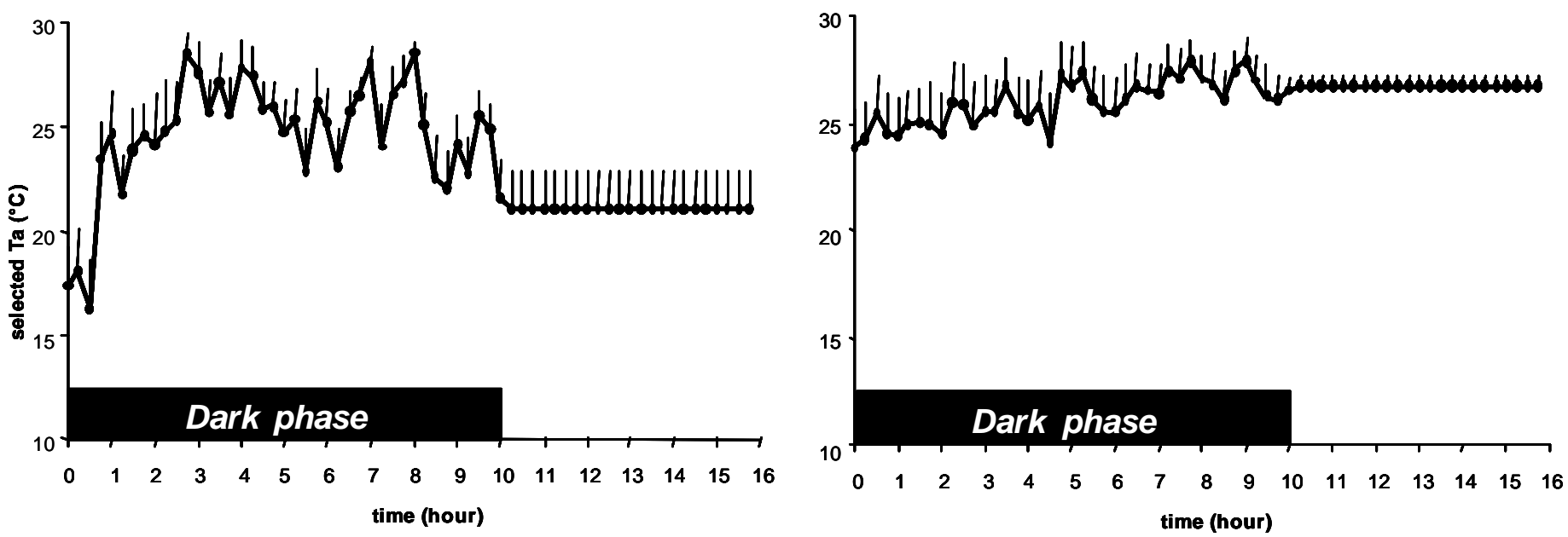

B
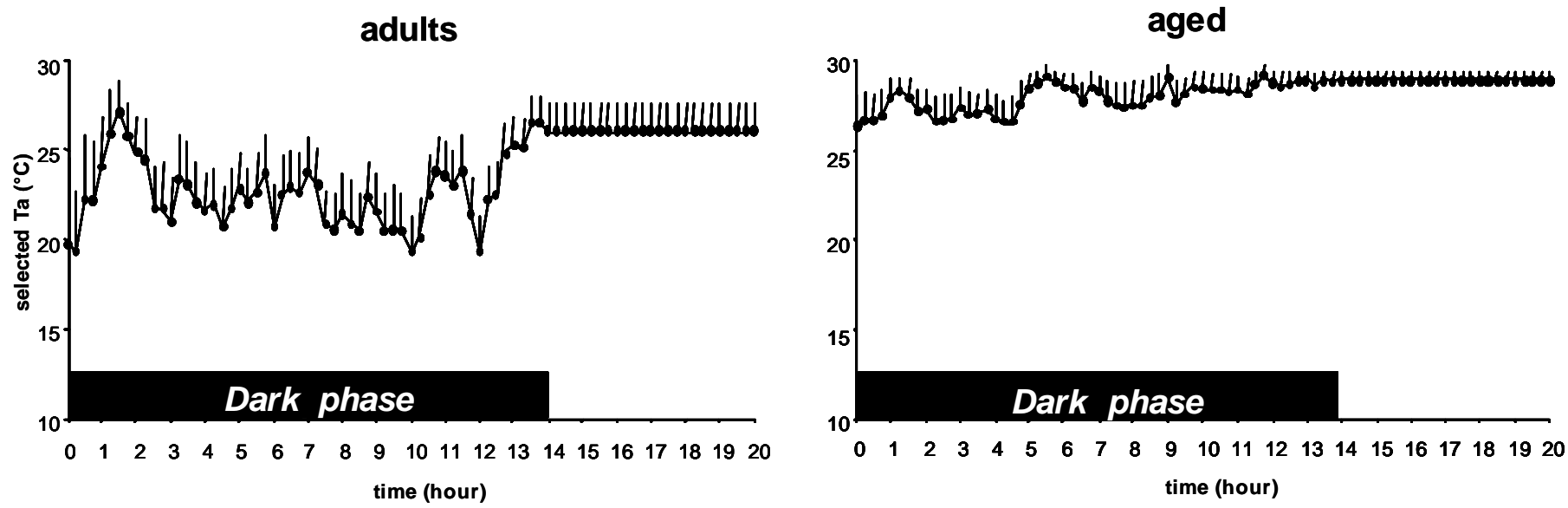
Fig. 4
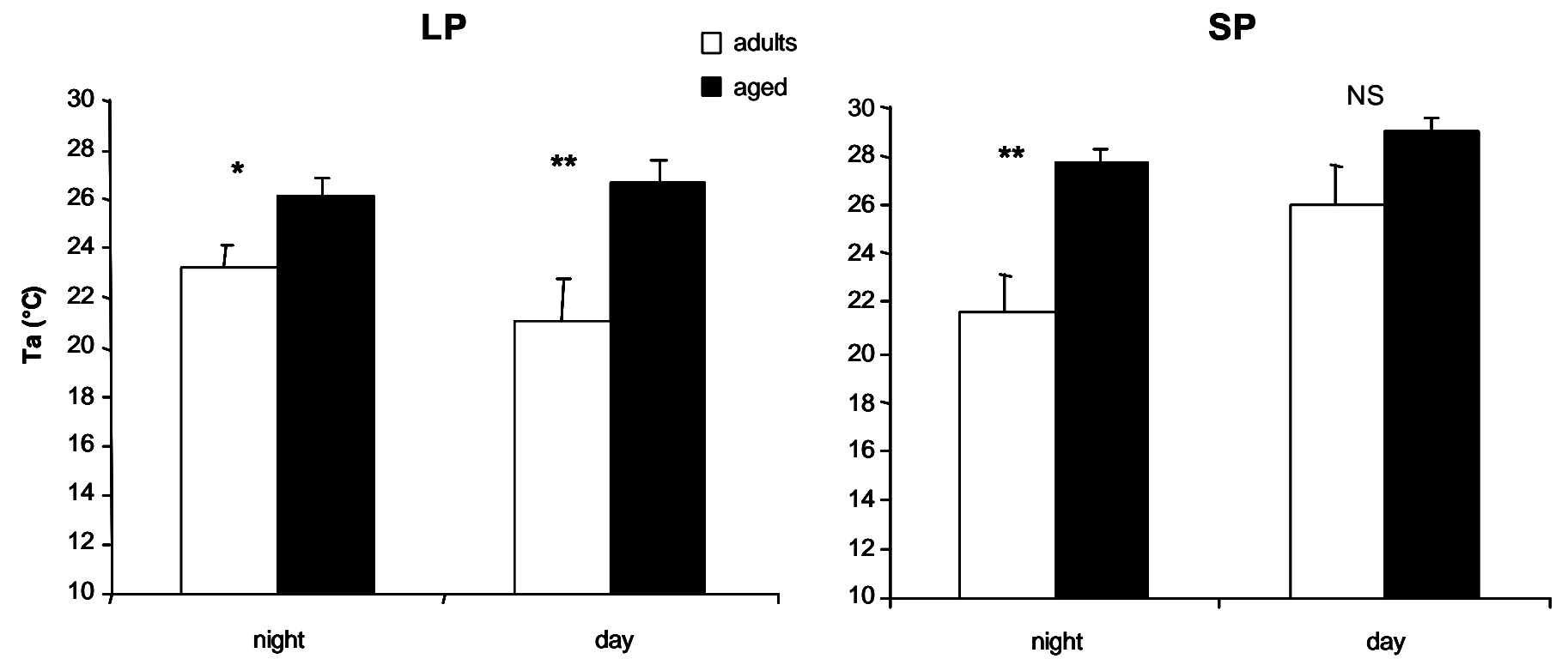
Fig. 5

A

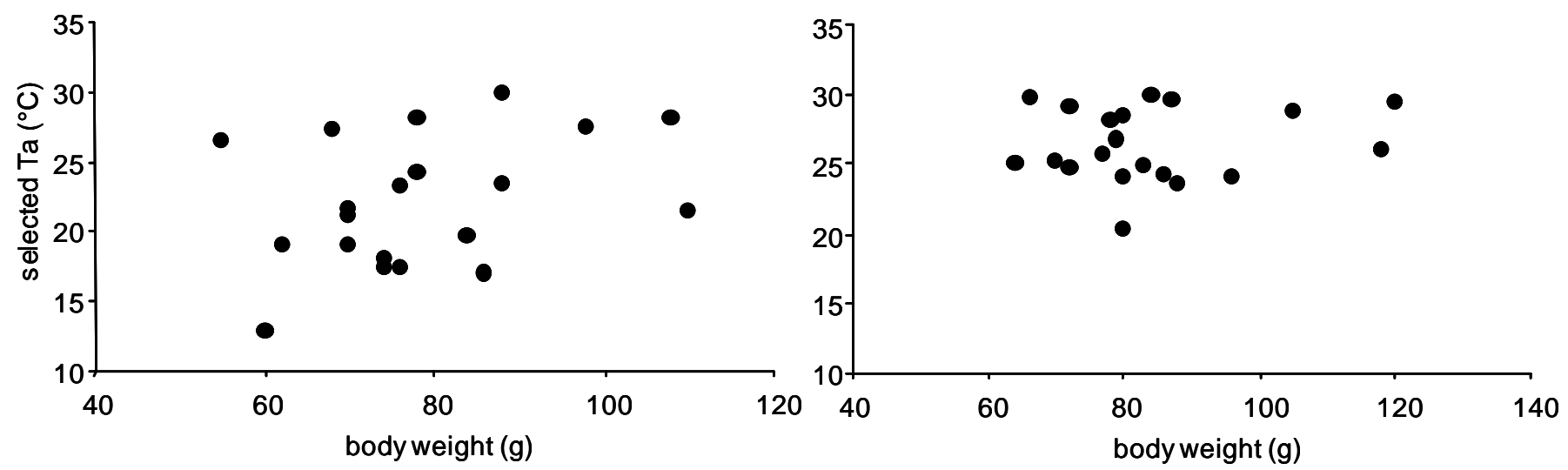

B

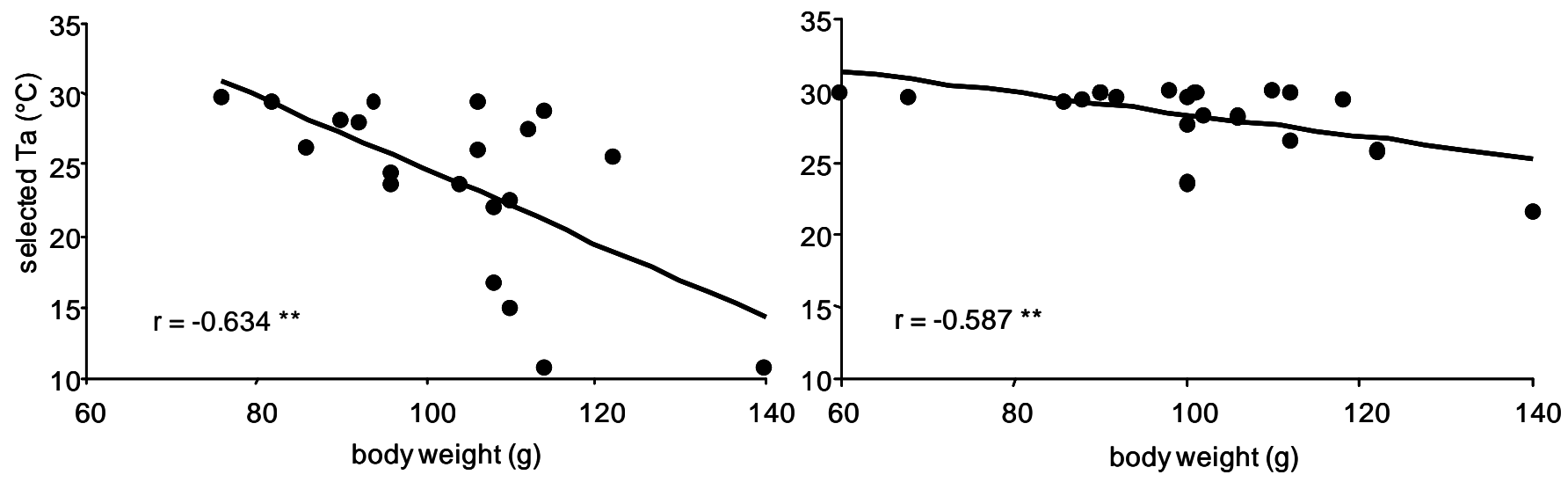


Fig. 6
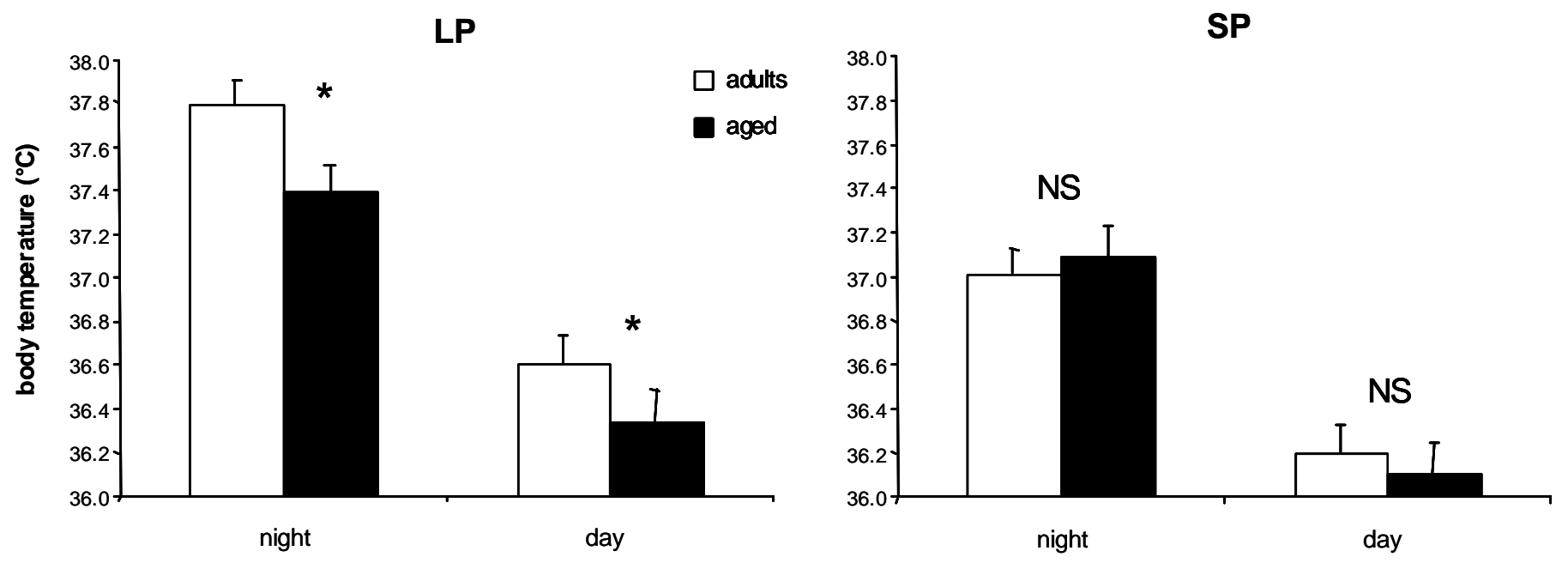